Nevşehir Bilim ve Teknoloji Dergisi Cilt 6(1) 20-29 2017

DOI: 10.17100/nevbiltek.309489

URL: http://dx.doi.org/10.17100/nevbiltek.309489

\title{
Avanos İlçe Merkezinde Trafik Kaynaklı Gürültü Kirliliğinin Mekansal Analizi
}

\author{
Erkan KALIPCI* \\ Nevşehir Hacı Bektaş Veli Üniversitesi, Çevre Mühendisliği Bölümü, Nevşehir
}

Öz

Bu çalışma ile; Nevşehir ili Avanos İlçe merkezinin ana arterlerinde trafik kaynaklı gürültü kirliliği seviyesinin tespit edilmesi ve yaşanan gürültü kirliliğinin insanlar üzerindeki olumsuz etkilerinin en az seviyeye indirilmesi için alınabilecek önlemler belirlenmiştir. Yapılan gürültü ölçümleri TS ISO 3744, TS ISO 1996-1 ve 1996-2 standartlarına uygun olarak yapılmıştır. Ölçüm istasyonlarında oluşan gürültü seviyeleri Svantek marka Tip I gürülttü ölçüm cihazı ile ölçülmüştür. Ayrıca, Avanos kent merkezinin gürültü kirliliği, Coğrafi Bilgi Sistemi (CBS) aracıllğıyla konumsal olarak değerlendirilmiştir. Toplam 24 adet ölçüm noktasında yapılan gürültü ölçümlerinde, ilçe merkezinde bulunan ana arterlerdeki (Kapadokya Caddesi, Vatan Caddesi, Atatürk Caddesi, Zelve Caddesi, Mithat Dülge Caddesi, Dereyamanlı Caddesi, İnönü Caddesi, Saruhan Caddesi) eşdeğer gürültü ölçüm seviyelerinin gündüz 79-85 dBA aralığında olduğu tespit edilmiştir. Avanos ilçesi giriş ve çıkışında D-300 Nevşehir-Kayseri Karayolunda yapılan ölçümlerde maksimum gürültü seviyesinin Lmax 109 dBA, minimum Lmin 82 dBA olduğu belirlenmiştir. İlçe merkezinde trafik kaynaklı gürültünün yaşandığı ana arterlerin iç kısmında kalan sokaklarda eşdeğer gürültü ölçüm seviyelerinin gündüz 48-65 dBA aralığında olduğu belirlenmiştir. Avanos İlçesi kent merkezinde bulunan ana caddeler ve D-300 Nevşehir-Kayseri Karayolunda bulunan ölçüm istasyonlarında belirlenen eşdeğer gürültü ölçüm seviyelerinin (Leq) 'Çevresel Gürültünün Değerlendirilmesi ve Yönetimi Yönetmeliği (ÇGDYY)’, OSHA, ISO, WHO'da belirtilen sınır değerlerin üzerinde olduğu ve insanların sağlığını tehdit eder boyuta geldiği tespit edilmiştir. Ana arterlere nispeten daha uzak olan iç kısımda bulunan sokaklarda yapılan ölçüm seviyelerinin ÇGDYY'e uygun bulunduğu belirlenmiştir. Ana arterlerde yapılan ölçümlerden elde edilen sonuçlar insan sağlığı açısından zararlı olduğundan, alınacak tedbirler kısaca belirtilmiştir.

Anahtar Kelimeler: Gürültü kirliliği, Trafik, Nevşehir, Avanos, Mekansal Analiz.

\section{Spatial Analysis of Traffic Related Noise Pollution in The Center of Avanos District}

Abstract

In this present study,the precautions that might be taken were determined for noise pollution levels sourced by main arterial roads of traffic in Avanos district center of Nevsehir city and to decrase the levels of the negative effects of noise pollution on human beings to lesser degrees. The nosie measurements were carried out according to TS ISO 3744, TS ISO 1996-1 and 1996-2 standards. In these noise measurements for total 24 measurement points, it was determined that equivalent noise measurement levels for the main arterial roads in the district centers were found between 79-85 dBA in the afternoons. In the entrance and exit of Avanos district, maximum noise level, Lmax and minimum noise level Lmin were determined for D-300 Nevşehir-Kayseri main road as 109 dBA and $82 \mathrm{dBA}$, respectively. In the avenues in the interial part of main arterial roads where traffic-sourced noise was experienced in the district center, equivalent noise measurement levels were determined as 48-65 dBA. It was stated for the equivalent noise measurement levels determined belonging to the measurement stations of the main roads in Avanos distric center and D-300 Nevşehir-Kayseri main road, it was determined that the levels were above the limit values specified by (Leq) 'Regulations for Evaluation and Management of Environmental Noise (REMEN)', OSHA, ISO, and WHO and at the levels which threaten the human health. It was also stated for the avenues in the interial part of main arterial roads that the measurement levels were in accordance with REMEN.

Keywords: Noise pollution, Traffic, Nevşehir, Avanos, Spatial analysis.

* e-mail: ekalipci@nevsehir.edu.tr 


\section{Giriş}

Gürültü çağımızın en önemli sorunlarından biri olmuştur. Eski çağlarda da gürültü bir "belâ" olarak insanların karşısında, önlenmesi gereken bir sorun olarak vardı. Roma şehrinin ozanları, gürültüyü satirik eserlerinde dile getirmişlerdir. XVI. yüzyılda Büyük Britanya Kraliçesi Elisabeth, çevreye gürültü yayılmasın ve kimse rahatsız olmasın diye, gece saat $22^{\underline{00}}$, den sonra, erkeklerin eşlerini dövmelerini yasaklamıştır. Tüberküloz mikrobunu bulan Robert KOCH 1910 yılında "Günün birinde insanlar, aynen kolera ve vebada olduğu gibi gürültüyle mücadele etmek zorunda kalacaklardır" demiştir. Son yıllarda aşırı gürültü yalnız hoşa gitmeyen ve rahatsızlık yaratan bir faktör olmanın ötesinde değişik özellikler kazanmaktadır. Günümüzde motorlu taşıtların olağanüstü yaygınlık kazanması, ulaşımın gelişmesi, üretim etkinliklerinde kullanılan araçların makineleşmesi, yaşama alanlarının gerektiğinde gürültüden korunmaması, toplum sağlığı açısından birçok sorunların doğmasına yol açmaktadır. 1940’lı yılların sonlarına kadar, sesin aşırılığı bir gürültü olarak görülmemiş, insan sağlığına etkileri önemsenmemiştir. İşlek yolların yakınlarında, hava alanlarının çevrelerinde yaşayanların bir gün gelip de geceleri rahatça uyuyamayacakları düşünülmemişti. 2000 yılına doğru, bilimin ve tekniğin gelişmesinin, uygarlığın bir paraziti olarak giderek büyüyen, çözümü zorlaşan sorunlardan biri, gürültü şeklinde belirginleşmektedir. Özellikle büyük şehirlerde yaşayanlar için gürültü büyük bir eziyet kaynağı olmuştur [1].

Ülkemizde gürültü kirliliği ile mücadele etmek için, 11.08 .1983 tarih ve 18132 sayılı Resmi Gazetede yayımlanarak yürürlüğe giren 2872 sayılı Çevre Kanunun 14. maddesine istinaden, 11 Aralık 1986 tarih ve 19308 sayılı Resmi Gazetede yayımlanarak yürürlüğe girmiş olan 'Gürültü Kontrol Yönetmeliği’ çıkarılmıştır [2]. 01.07.2005 tarih ve 25862 sayılı Resmi Gazetede 'Çevresel Gürültünün Değerlendirilmesi ve Yönetimi Yönetmeliğgi'nin yayımlanarak yürürlüğe girmesinden sonra ise 'Gürültü Kontrol Yönetmeliği’ yürürlükten kaldırılmıştır [3]. Yine 04.06.2010 tarih ve 27601 sayılı Resmi Gazetede 'Çevresel Gürültünün Değerlendirilmesi ve Yönetimi Yönetmeliği’ revize edilerek yayınlanmış olup pek çok uygulamada karşılaşılan eksiklikler giderilmeye çalışılmıştır [4]. Ayrıca 12 Ekim 2004 tarihli Resmi Gazetede yayımlanarak yürürlüğe giren 5237 sayılı Türk Ceza Kanunun 183.maddesi ile 'İlgili kanunlarla belirlenen yükümlülüklere aykırı olarak, başka bir kimsenin sağlığının zarar görmesine elverişli bir şekilde gürültüye neden olan kişi, iki aydan iki yıla kadar hapis veya adli para cezası ile cezalandırılır' hükmü getirilmiştir [5].

Günümüze kadar yapılan imar planlarının yanlışlığından ya da uygulama hatalarından dolayı birçok ilimizde önüne geçilmesi imkânsız hale gelen yanlış şehirleşmeler olmuştur. Bazı illerimizin birçok yerinde, özellikle trafik yükü fazla olan yerlerde, yolların genişlikleri 8-9 m civarında iken, aynı caddelerde binalar 6-8 kat arasındadır [6]. Burada, ses dalgalarının temas yüzeyi artmaktadır ve bu durumda oluşan kirliliği gidermek için oldukça fazla parasal kaynağa ihtiyaç vardır [7].

Kent peyzajlarında trafik, önemli derecede gürültü rahatsızlıkları meydana getirmektedir. Kentlerde gürültüye karşı mücadele için, önce gürültünün kaynakları ve şiddeti hakkında bilgi toplanması gerekmektedir. İnsanlar, 30-60 dBA seslere karşı kişisel hassasiyete de bağlı olarak çeşitli şekillerde etkilenmekte, daha yüksek değerler olduğunda etkiler de beraberinde artmaktadır [8]. Gürültüden etkilenme konusunda OECD’nin 1996 yılında yayımladığı raporda, gürültünün 55-60 dBA dolaylarında rahatsızlık oluşturmaya başladığı, 60-65 dBA arasında rahatsızlığın belirgin bir biçimde arttı̆gı, $65 \mathrm{dBA}$ üzerinde ise önemli sağlık problemlerine ve davranış bozukluklarına yol açtı̆̆ı belirtilmektedir [9]. 
Brezilya'da 860 katılımcı ile düzenlenen anket çalışmasında, katılımcılara 'Hangi gürültü kaynakları sizi rahatsız etmektedir ?' sorusu yöneltilmiş ve katılımcıların \%73'nün trafik gürültüsünden rahatsız oldukları tespit edilmiştir [10]. Şehir planlamaları yapılırken, endüstriyel gürültü kaynaklarının ve otoyolların yaşam alanlarından ayrı tutulmasını sağlayacak uygulamalara özen gösterilmelidir [11]. Yapılan araştırmalar sonucunda; İsveç'de cadde kenarlarında yaşanan gürültü kirliliğinden dolayı evlerin satış fiyatlarının \%30 oranında değer kaybettiği tespit edilmiştir [12]. Avrupa ülkelerini kapsayan bir çalışmada ise, hazırlanan ayrıntılı gürültü haritaları yardımı ile, söz konusu ülkelerde yaşayan toplam 371 602000 kişiden \%32'sinin $55 \mathrm{dBA}$, \%13'ünün ise $65 \mathrm{dBA}$ üzerindeki gürültülerden etkilendiği belirlenmiştir [9]. Ali ve Tamura Mısır'ın Greater Cario şehrinde 21 farklı ölçüm noktası belirleyerek gürültü ölçümleri yapmış ve eşdeğer gürültü seviyelerini (Leq) tespit etmiştir. Ölçüm yaptığı noktalarda sırası ile önce korna yasağı, daha sonra korna ve kamyonların geçiş yasağı ve en sonunda da korna, kamyon ve otobüs geçişi yasağı yaptırımlarından sonra Leq değerlerini tespit ederek yaptırımlardan önceki ölçüm değerleri ile kıyaslamıştır [13]. Buratti ise yapmış olduğu çalışmada, sıcak iklim kuşağında yer alan bölgelerde pencerelerin açık tutulduğunu bu durumun ise iç ortamın gürültü düzeyinin trafik gürültüsünün etkisi ile arttığını tespit etmiştir [14].

Karadayı yapmış olduğu çalışmada; Bursa ili merkez Nilüfer, Osmangazi ve Yıldırım ilçelerinde toplam 51 adet ölçüm noktası belirleyerek, gürültü ölçümleri yapmıştır. Nilüfer, Osmangazi ve Yıldırım ilçelerinde bulunan ana arterlerden kaynaklanan gürültü seviyelerinin rahatsız edici boyutlara ulaştığını tespit ederek trafik kaynaklı gürültü haritasını hazırlamıştır [15]. Bunun yanı sıra; Aktürk ve arkadaşları karayolu ulaşımının önemli yan etkilerinden biri olan çevresel ulaşım gürültüsünün kaynakları, insanlar üzerindeki etkileri ve bu tür gürültünün trafik 1şık süresi ile değişimini incelemiştir. Ankara'daki Kızılay ve Ulus kavşaklarını modelleyerek, bu kavşaklar etrafında seçilen tipik bazı noktalardaki gürültü seviyelerini hesaplamıştır. Elde ettiği sonuçlar trafik ışık süre planlamasında yapılan hataların yan etki olarak gürültüye neden olduğu ve yol gösterici bir parametre olarak gürültünün de dikkate alınmasının yerinde olacağını göstermiştir [16]. Kalıpcı ve ark. ise yapmış oldukları çalışmalarda Trabzon, Giresun ve Konya illerinde trafik kaynaklı gürültü kirliliklerini tespit ederek, gürültü seviyesinin birçok noktada sınır değerleri aştığını tespit etmiştir [17-20].

Yapılan bu çalışma ile, Nevşehir ili Avanos ilçe merkezinde bulunan mevcut karayolları ve şehir içi ana arterler üzerinde ölçüm istasyonları belirlenerek, belirlenen ölçüm istasyonlarının koordinatları GPS cihazı ile tespit edilmiştir. Belirlenen ölçüm istasyonlarından yayılan karayolu trafik gürültü seviyeleri gürültü ölçüm cihazı ile ana arterlerde ölçülmüştür. Gürültünün azaltılması ve kontrol altına alınması için gerekli tedbirler ortaya konmuştur.

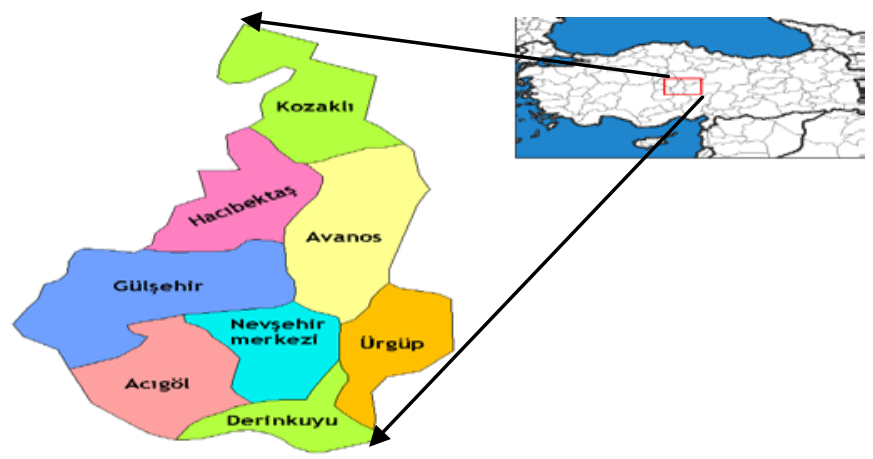

Şekil 1. Avanos ilçesinin şehir ve ülkedeki yeri [22] 


\section{Materyal ve Metot}

Çalışma alanı olarak seçilen Avanos, İç Anadolu Bölgesi’nde 38²12' ve 39²0' kuzey enlemleri ile $34^{\circ} 11^{\prime}$ ve $35^{\circ} 06^{\prime}$ doğu boylamları arasında yer alan Nevşehir İli' ne bağlı bir ilçedir [21]. Çalışma alanı olan Avanos ilçesinin, şehir ve ülkedeki yerini gösterir harita Şekil 1'de verilmiştir.

Nevşehir kenti Avanos ilçe merkezinde, özellikle trafikten kaynaklanan gürültü seviyelerinin belirlenmesi amacıyla, işyerlerinin ve trafiğin yoğun olduğu ana yollar, kavşaklar ve bağlantı yolları üzerinde 24 ayrı ölçüm istasyonu belirlenmiştir. Gürültü ölçümü yapılan ölçüm istasyonlarının koordinatları ise Magellan Explorist 710Map el tipi GPS alıcısı ile tespit edilmiştir. Gürültü seviyesi ölçümleri için, kalibrasyonu Svantek SV 33 model kalibratör ile yapıllmış olan Svantek 971 marka Tip 1 gürültü seviyesi ölçüm cihazı kullanılmıştır. Cihazın max. pik. ses basınç seviyesi 141dBA olup, 25-141 dBA aralığındaki gürültü seviyelerini ölçebilmektedir. Belirlenen ve koordinatları alınan 24 adet ölçüm istasyonunda (ölçüm noktasında) 2016 yılı Ocak-Nisan aylarında trafiğin yoğun olduğu 08.00-18.00 saatleri arasında gürültü ölçümleri yapılmıştır. Ölçümler gürültü seviyesi ölçülecek yolun veya kavşağın kenarında bulunan kaldırımların yola bakan kenarlarında yerden 1.5 metre yükseklikte yapılmıştır. Koushki ve ark. [23], Baaj ve ark. [24] 1.5 m yükseklikten ölçümleri yapar iken, Onuu [25] ve Leong ve ark. [26] 1.2 m yükseklikten ölçüm yapmıştır. Dursun ve Özdemir [27] ise ölçümleri kulak seviyesi olan yerden 1.65-1.80 m yükseklikte yapmıştır.

Google Earth Pro’ dan yüksek çözünürlük kalitesinde temin edilen Nevşehir ili Avanos ilçesi uydu görüntüsünden yararlanarak, Avanos ilçesinin yerleşim alanı ArcMAP yazılımda sayısallaştırılmış ve 24 adet gürültü ölçüm istasyonu sayısallaştırılmış alan üzerine koordinatları ile işlenmiştir. Gürültü ölçüm istasyonlarında belirli zaman aralıkları ile ölçülen 5 farklı ölçümün ortalama değerleri belirlenerek öznitelik tablosu oluşturulmuştur. Oluşturulan öznitelik tablosundaki ortalama değerler ArcMAP'te oluşturulan ölçüm istasyonlarına aktarılmıştır. Ölçüm istasyonlarına işlenen sonuçlar kullanılarak, ArcMAP yazılımının Spatial Analyst Tools sekmesinde bulunan IDW (Ters Mesafe Ağırlıklı)‘ den faydalanılarak gürültü haritası oluşturulmuştur.

\section{Bulgular}

Gürültü ölçümü yapılan ölçüm istasyonlarının koordinatları Explorist 710 Map el tipi GPS alıcısı ile tespit edilmiş olup ölçüm istasyonlarının koordinatları aşağıda Tablo 1' de listelenmiştir. Gürültü ölçüm noktalarını gösterir harita ise Şekil 2' de verilmiştir.

Yapılan gürültü ölçümleri TS ISO 3744, TS ISO 1996-1 ve 1996-2 standartlarına uygun olarak yapılmıştır. Gürültü seviyesi olarak, eşdeğer gürültü seviyesini ifade eden Leq değeri ölçülmüştür. Yapılan ölçümler neticesinde, her ölçüm noktasında 5 adet eşdeğer gürültü ölçümü yapılmıştır. Eşdeğer gürültü ölçümü seviyelerinin (Leq) ortalamaları bulunarak, ölçüm istasyonlarının gürültü seviyeleri tespit edilmiştir. Ölçüm sonuçlarının ortalamaları alınarak belirlenen gürültü seviyeleri aşağıda Tablo 1'de sunulmuştur.

Google Earth Pro' dan yüksek çözünürlüklü, metrik koordinat sistemine bağlı WGS84 - Zone 36 koordinat düzleminden alınan JPEG formatındaki uydu görüntüsü ArcMAP ortamına aktarılmıştır. Görüntü üzerinde Avanos İlçesinin sınırları ve gürültü ölçüm noktaları sayısallaştırılarak vektör veri haline getirilmiştir. Gürültü ölçüm sonuçları tablo haline getirilerek öznitelik verisi olarak ArcMAP' te Avanos ilçesi üzerinde yapılan sayısallaştırılmış vektör veri üzerine aktarılmıştır. Sayısallaştırılan vektör 
veri ve üzerine eklenen öznitelik tablosu kullanılarak ArcMAP' te tematik haritalar ve verilere bağl1 grafikler oluşturulmuştur. Daha sonra 04.06.2010 tarih ve 27601 sayılı Resmi Gazetede 'Çevresel Gürültünün Değerlendirilmesi ve Yönetimi Yönetmeliği'ndeki sınır değerlere göre yorumlanarak ve Gürültü Kirliliği Haritası hazırlanarak Şekil 3' de verilmiştir.

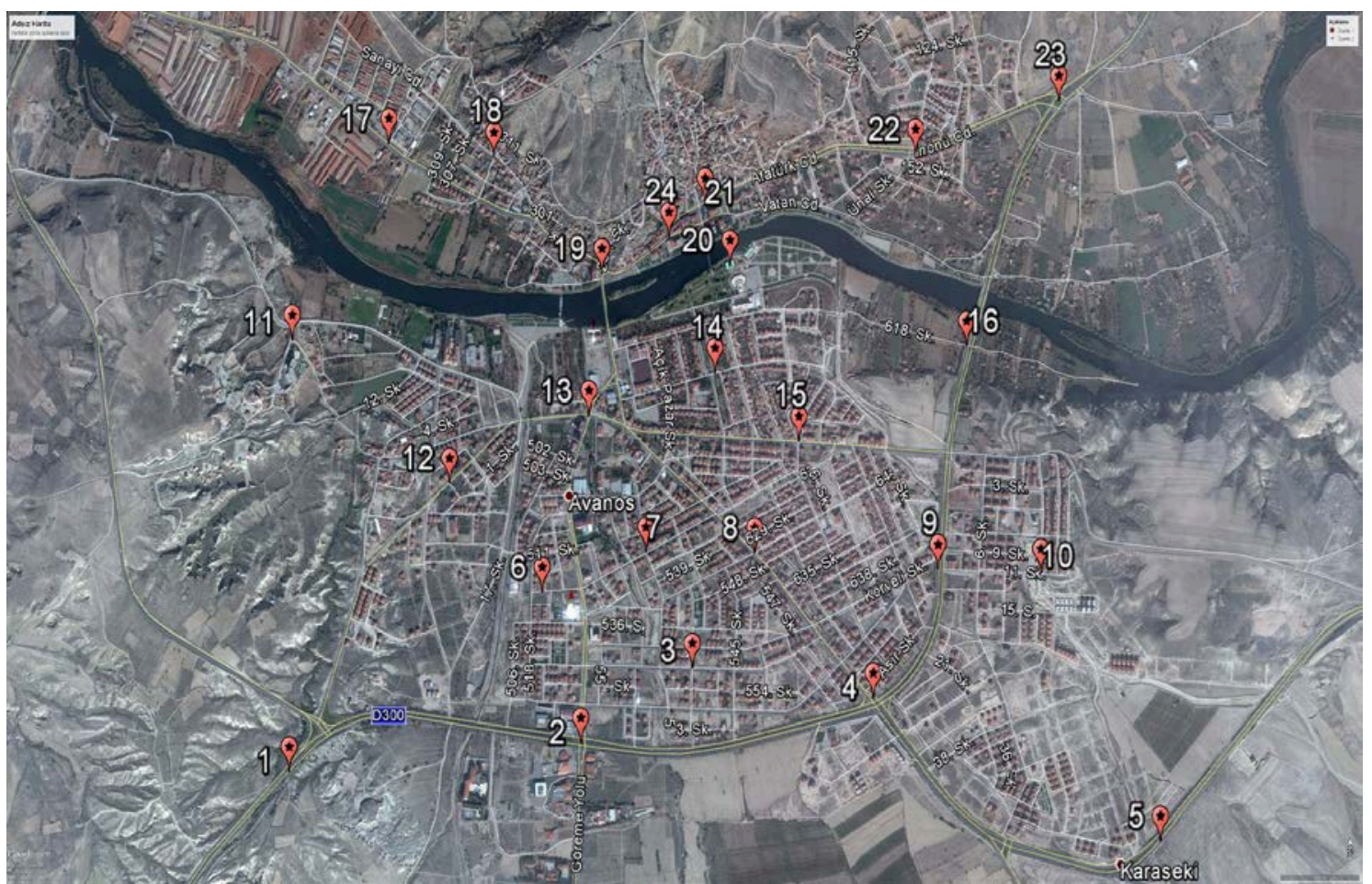

Şekil 2. Google Earth'de ölçüm noktalarının koordinatları

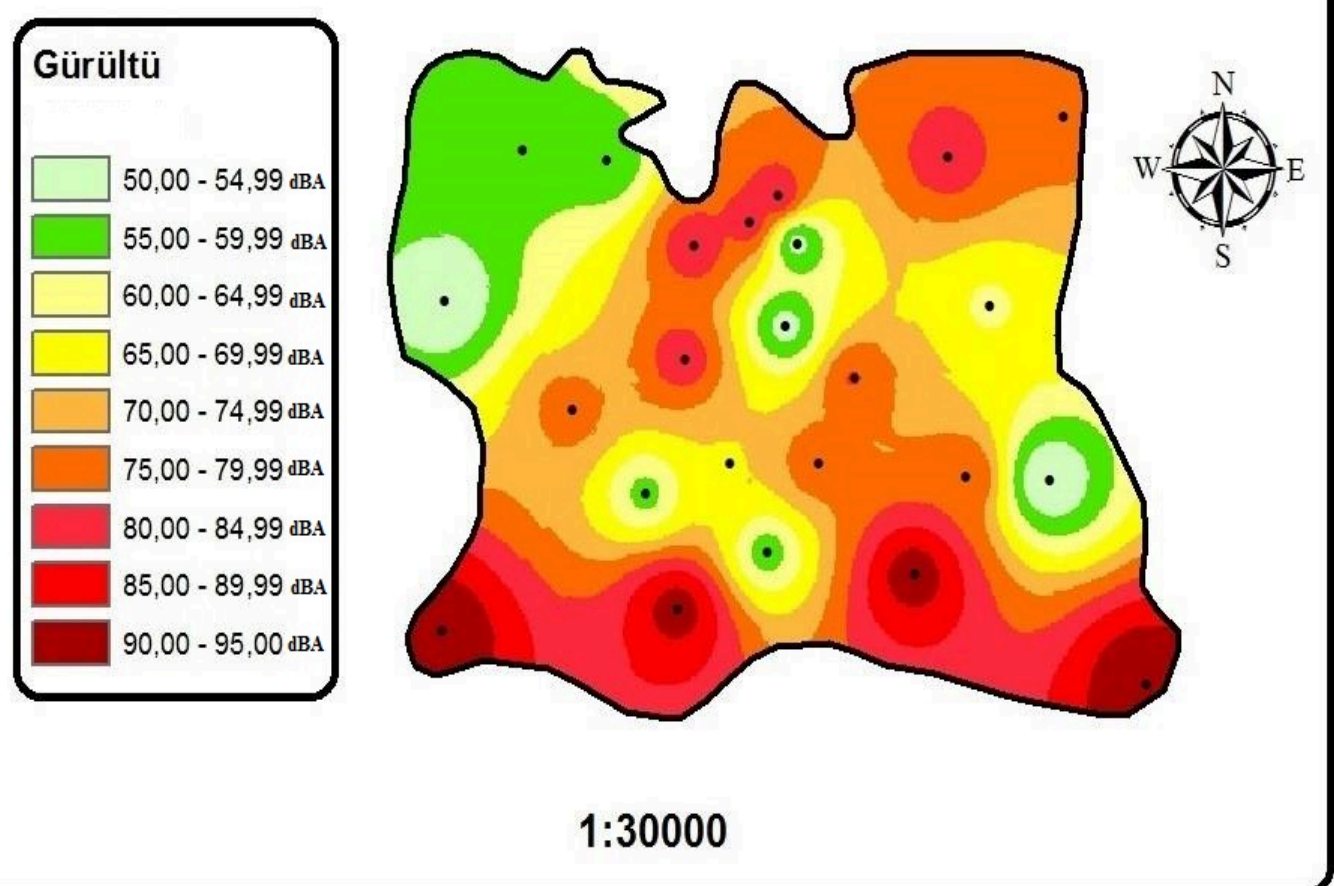

Şekil 3. Gündüz 08.00-18.00 saatleri arasında ölçülen gürültü seviyelerinin mekansal dağılımı 
Tablo 1. Gürültü ölçümleri (Leq değerleri, $\mathrm{dBA}$

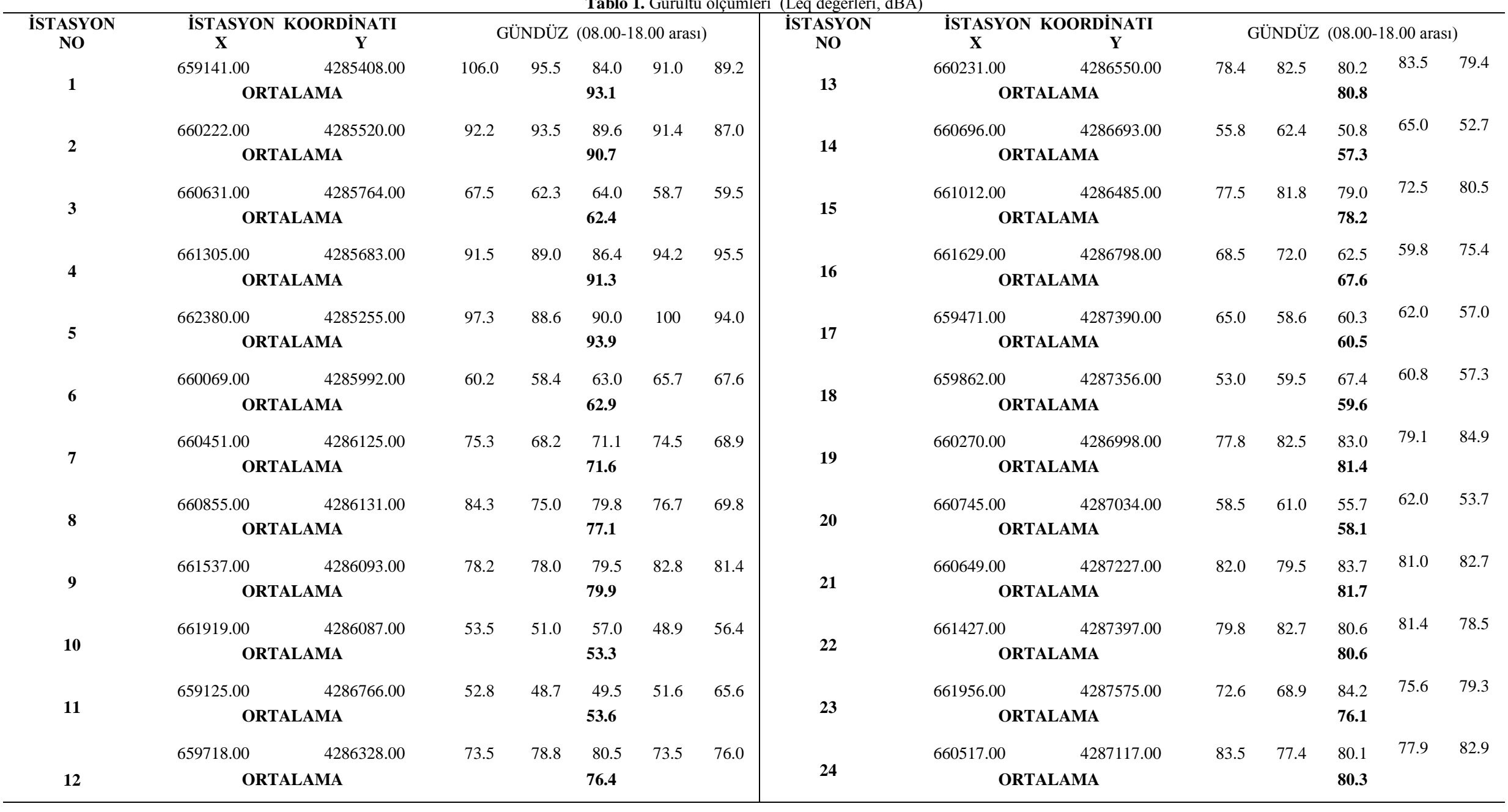




\section{Tartışma ve Sonuç}

04.06.2010 tarih ve 27601 sayılı Resmi Gazetede 'Çevresel Gürültünün Değerlendirilmesi ve Yönetimi Yönetmeliği' ndeki sınır değerler dikkate alınarak aşağıdaki değerlendirmeler yapılmıştır.

Nevşehir ili Avanos ilçe merkezinde ana gürültü kaynağı öncelikle trafik gürültüsüdür. Avanos ilçesinde turizm sektörü kaynaklı karayolları taşımacılığının günden güne artması, çeşitli kara nakil araçlarının büyük ölçüde kullanılması trafik gürültüsünün şiddetini de arttırmıştır.

İlçe merkezinde bulunan mevcut ana caddeler dar olmakla birlikte araç yoğunlukları fazla olduğundan, cadde genişliğinin yeterli olmaması nedeniyle araçların yol kenarına park edilmesi gibi etkilerle trafik kesintisi ve gereksiz korna çalınması sonucu trafik yoğunluğu fazla bir hal almıştır. Şehir merkezinde yeterli otopark da bulunmamaktadır. Araçlar cadde ve meydanlara rastgele park etmekte veya park etmek amacıyla gereksiz yere dolaşarak gürültü arttırıcı rol oynamaktadır. Merkezde ağaçlandırma yok denecek kadar az olduğundan dolayı gürültüyü emme avantajından da yararlanılamamaktadır. Karayolu kenarlarında gürültü etkisini azaltmak üzere gürültü bariyeri veya plântasyon çalışmaları yapılmamıştır. İlçede yerleşim bölgelerinde gürültü seviyeleri caddelere, sokaklara, ticarethanelerin yoğun olduğu yerlere göre değişim göstermektedir. Ayrıca; piknik alanları, çay bahçeleri, gazinolar, lokantalar v.b. eğlence tesislerinde gerek işletme sahibinin bilinçsizliği gerekse çevreye duyarsız insanların müzik dinlerken sesini sonuna kadar açmaları gürültü kirliliğine sebep olmaktadır.

Toplam 24 adet ölçüm noktasında yapılan gürültü ölçümlerinde, ilçe merkezinde bulunan ana arterlerdeki (Kapadokya Caddesi, Vatan Caddesi, Atatürk Caddesi, Zelve Caddesi, Mithat Dülge Caddesi, Dereyamanlı Caddesi, İnönü Caddesi, Saruhan Caddesi) eşdeğer gürültü ölçüm seviyelerinin gündüz 7985 dBA aralığında olduğu tespit edilmiştir. Avanos ilçesi giriş ve çıkışında D-300 Nevşehir-Kayseri Karayolunda yapılan ölçümlerde maksimum gürültü seviyesinin Lmax 109 dBA, minimum Lmin 82 dBA olduğu belirlenmiştir. İlçe merkezinde trafik kaynaklı gürültünün yaşandığı ana arterlerin iç kısmında kalan sokaklarda eşdeğer gürültü ölçüm seviyelerinin gündüz 48-65 dBA aralığında olduğu belirlenmiştir. Avanos ilçesi merkezinde bulunan ana caddeler ve D-300 Nevşehir-Kayseri Karayolunda bulunan ölçüm istasyonlarında belirlenen eşdeğer gürültü ölçüm seviyelerinin (Leq) Çevresel Gürültünün Değerlendirilmesi ve Yönetimi Yönetmeliği (ÇGDYY), OSHA, ISO, WHO’ da belirtilen sınır değerlerin üzerinde olduğu ve insanların sağlığını tehdit eder boyuta geldiği tespit edilmiştir. Ana arterlere nispeten daha uzak olan iç kısımda bulunan sokaklarda yapılan ölçüm seviyelerinin ÇGDYY' e uygun bulunduğu belirlenmiştir.

Çevresel gürültünün etkisinin azaltılması için bazı önlemler alınabilir. Özelikle trafik açısından; yol kaplamaları değiştirilebilir, kavşak dönemeç ve 1şıklar düzenlenerek trafiğin durmaksızın akışı sağlanabilir ya da minimun duruş sağlanabilir, trafiğin yoğun olduğu yerlerdeki yoğunluğu daha az yoğun yerlere çekilmesi ile trafik yoğunluğu azaltılabilir. Alınacak bu önlemler ile çevresel gürültünün azalması sağlanacaktır [9].

Nevşehir ili Avanos ilçesinde sit alanı sahasının fazla olması nedeniyle konut yapılacak uygun arazi bulunmasında güçlük çekilmektedir. Bu nedenle de kent merkezinde son derece çarpık ve plânsız bir kentleşme hâkimdir. Bitişik nizamda yapılan konutların bulunduğu alanlarda caddeler de geniş olmadığından gürültü yankılayıcı özellik göstermekte ve çevrede yaşayanlar gürültüden daha fazla etkilenmektedirler. Plânsız yapılaşmanın önüne geçilmesi ve bitişik nizamda yapılan konutlara mümkün 
olduğunca izin verilmemesi gerekmektedir.

Yeni yapılacak olan binalarda izolâsyona daha fazla önem verilerek, binaların inşaatı aşamasında ses yalıtımı sağlayan malzemelerin kullanılması sağlanmalı ve özendirilmelidir. Ayrıca, binalarda çift cam uygulaması zorunlu hale getirilmelidir. Belediyelerce binalarda ses izolâsyonunu sağlayacak malzemelerin kullanılıp kullanılmadığı titizlikle kontrol edilmelidir.

Şehrin merkezinde ağaçlandırma yok denecek kadar az olduğundan dolayı gürültüyü emme avantajından yararlanılamamaktadır. Yerleşim alanlarının çevrelerine ağaçlandırma ve bitki örtüsü çalışması yapılmak suretiyle gürültünün olumsuz etkisi azaltılmalıdır.

Gürültüye neden olan işyerlerinin (ekmek fabrikaları, findık fabrikaları, kafeler, lokanta, araç yıkama yerleri, eğlence yerleri ve benzeri işyerlerinin) konutların alt katlarında veya konutların yakınında kurulmasına izin verilmemesi gerekmektedir. Mevcut işyerleri içinde gerekli gürültü izolasyonunun yaptırılması sağlanmalıdır.

İlçe merkezinde yeterli otopark bulunmadığından, araçlar cadde ve meydanlara park etmek amacıyla gereksiz yere dolaşarak gürültü arttırıcı rol oynamaktadır. Bu bakımdan şehir merkezinde yeteri sayıda otoparklar yapılmalıdır.

İlçe Emniyet Müdürlüğü ekiplerince şehir içerisinde; düğünlerde, asker uğurlamalarında, maçlarda, araçların konvoy oluşturup korna çalarak, patlayıcı maddeler ve silah atarak gürültü kirliliği oluşturmaları engellenmeli ve araçlarda yüksek sesle müzik dinlenmesine müsaade edilmemelidir.

İlçe içinde bulunan yolların bakımsız olması, çok fazla sayıda kü̧̈ük çukurların bulunması sebebiyle, araçlar ani fren yapmakta ve bu durumda gürültü kirliliğine neden olmaktadır. Bu bakımdan şehir içinde bulunan yollarda ivedilikle tadilat çalışmaları yapılarak, yolların iyileştirilmesi gerekmektedir.

Araçların gereksiz yere korna çalmaları engellenerek, araçların fenni muayenesi sırasında susturucu ve ses önleyici düzeneklerinin titizlikle kontrolü yapılması gerekmektedir. Ayrıca yapılan bu kontroller sırasında, araçların egzozlarına ses çıkarması için özellikle takılan, ıslık vb. ad verilen tertibatların ve havalı korna gibi yüksek ses çıkaran klaksonların da araçlardan çıkarttırılması sağlanmalıdır.

Şehirlerimizde yaşanan gürültü kirliliklerini önlemek için Ülke genelinde ivedilikle gürültü kirliliği haritalarının hazırlanarak mevcut durum tespiti yapılmalıdır. Akabinde ise eylem planları oluşturularak, gürültü kirliliği yaşanan bölgelere yönelik kısa, orta ve uzun vadede alınacak önlemler belirlenip uygulamaya geçirilmelidir. Şehir merkezlerinde geleceğe dönük olarak ulaşım planlamaları yapılırken ana arterlerin gürültü kirliliği faktörleri de göz önünde bulundurularak trafik akışı planlanması, gürültüyü azaltmada olumlu etki yaratacaktır. Gürültü azaltım planlamasının, şehir planlamalarına entegrasyonu sağlanarak çevre ve insan sağlığına olası olumsuz etkileri minimuma indirilmelidir.

Ayrıca, 2872 sayılı Çevre Kanununa istinaden çıkartılıp, yayımlanarak yürürlüğe giren 'Çevresel Gürültünün Değerlendirilmesi ve Yönetimi Yönetmeliği' hükümlerinin titizlikle takibinin yapılarak, uygulamaya geçirilmesi sağlanmalıdır.

\section{Teşekkür}

$\mathrm{Bu}$ araştırmada NEÜBAP15F3 numaralı projemize verdiği desteklerden dolayı Nevşehir Hac1 Bektaş Veli Üniversitesi Bilimsel Araştırma Projeleri (BAP) Koordinatörlüğü’ne teşekkürlerimi sunarım. 


\section{Kaynaklar}

[1] Günay, E., 'Ses Kirlenmesi veya Desibel Cehennemi’, Çevre ve Insan Dergisi, Sayı No:20, Sayfa No:7-8, 1995.

[2] Anonim, 'Gürültü Kontrol Yönetmeliği', 11 Aralık 1986 Tarihli ve 19308 Sayılı Resmi Gazete, 1986, Ankara.

[3] Anonim, 'Çevresel Gürültünün Değerlendirilmesi ve Yönetimi Yönetmeliği', 01.07.2005 Tarih ve 25862 Sayılı Resmi Gazete, 2005, Ankara.

[4] Anonim, 'Çevresel Gürültünün Değerlendirilmesi ve Yönetimi Yönetmeliği', 04.06.2010 Tarih ve 27601 Sayılı Resmi Gazete, 2010, Ankara.

[5] Anonim, Türk Ceza Kanunu, 12.10.2004 Tarih ve 25611 Sayılı Resmi Gazete, 2004, Ankara.

[6] Özdemir,C., Burdurlu,Y., Işık, M., 'Yapı Elemanlarının ve İmar Planlarının Gürültü Kirliliği Üzerine Etkileri’, II. Biyologlar Derneği Kongresi, Kırşehir, 1997.

[7] Dursun, Ş., Özdemir, C., 'Konya İl Merkezinde Gürültü Kirliliği Haritasının Hazırlanması', Proje No:97-081, Sayfa No:4-24, Konya, 1999.

[8] Özdemir,C., Burdurlu, Y., 'Boyutları ve Etkileri Açısından Gürültü Kirliliği', Çevre Sempozyumu, S.Ü.Çevre Mühendisliği Bölümü, Konya, 1994.

[9] Akdağ, N., 'Kent Planlamada Gürültü Haritalarının Önemi: Barbaros Bulvarı Çevresi Örneği’, 6. Ulusal Akustik Kongresi, Antalya, 2002.

[10] Calixto, A., Diniz F.B., Zannin, P.H.T., 'The Statistical Modeling of Road Traffic Noise in an Urban Setting, Cities, Vol.20, No.1, p.23-29, 2003.

[11] Özer, V., Gürültü Kirliliği, Tübitak Bilim ve Teknik Dergisi,(337),72-77, 1995.

[12] Wilhelmsson, M., 'The Impact of Trafic Noise on The Values of Single-Family Houses, Journal of Enviromental Planning and Management, 43 (6), p. 799-815, 2000.

[13] Ali, S.A., Tamura, A., 'Road Traffic Noise Levels, Restrictions and Annoyance in Greater Cairo Egypt', Aplied Acoustics, 64, p. 815-823, 2003.

[14] Buratti, C., 'Indoor Noise Reduction Index with Open Window', Applied Acoustics, 63, p.431451, 2002.

[15] Karadayı, S., ‘Bursa İlinin Trafik Kaynaklı Gürültü Haritasının Hazırlanması', Yüksek Lisans Tezi, Sakarya Üniversitesi, Sayfa No:3-38, Sakarya, 2001.

[16] Aktürk, N., Akdemir, O.,Üzkurt, İ., 'Trafik Işık Sürelerinin Neden Olduğu Çevresel Taşıt Gürültüsü’, Gazi Ün..Müh.-Mim.Fak.Dergisi, Cilt 18, No.1,s.71-87, 2003.

[17] Kalıpc1, E., Dursun, Ş., 'Presentation of Giresun city traffic noise pollution map via geographical information system’, Journal of Applied Sciences, 9(3):479-487, 2009.

[18] Kalıpc1, E., Dursun, Ş., Özdemir, C., 'Road traffic noise pollution measurements of Trabzon city centre at black sea border', “ $7^{\text {th }}$ International Scientific Conference SGEM”, Conference Collection of Papers, Page number:162, Varna-BULGARIA, 11-15 June, 2007. 
[19] Kalıpc1, E., Dursun, Ş., 'Giresun ve Trabzon il merkezlerinin trafik kaynaklı gürültü kirliliklerinin karşılaştırılması’, Blacksea International Environmental Symposium BIES’08, Proceeding Book Volume II, Page number:544-552, Giresun-TURKEY, 25-29 August, 2008.

[20] Özdemir, C., Kalıpcı, E., 'Kentlerde yaşanan trafik kaynaklı gürültü kirliliği ve çözüm önerileri', İçişleri Bakanlığı Emniyet Genel Müdürlüğü, Karayolu Trafik Güvenliği Sempozyum ve Fuarı, Sayfa No:22, Ankara-TÜRKIYE, 10-12 Mayıs, 2011.

[21] Anonim, "2013 Yı1ı Nevşehir İl Çevre Durum Raporu", 1-107, Nevşehir, Nevşehir Çevre ve Şehircilik İl Müdürlüğü, 2014.

[22] Anonim, https://tr.wikipedia.org/wiki/Avanos\#/media/File:Avanos,_Nev\%C5\%9Fehir_haritas\%C4\%B1.s vg, 12.04.2016.

[23] Koushki, P.A., “Trafficnoise in Kuwait: Profilesand model in gresidents’ perceptions”, Journal of Urban Planning and Development, 101-109, 1999.

[24] Baaj, M.H., El-Fadel, M., Shazbak, S.M., Saliby, E., "Model in gnoise at elevated highways in urban areas: a practical application”, Journal of Urban Planning and Development, 169, 2001.

[25] Onuu, M.U., "Road traffic noise in Nigeria: Measurements, analysis and evaluation of nuisance" Journal of Sound and Vibration, 233(3), 391-405, 2000.

[26] Leong, S.T.,Lartanakul, P., "Monitor in gandas sess ment of daily exposure of road side worker stotraffic nois elevels in an asiancity: a casestudy of Bangkok streets”, Environemental Monitoringand Assessment, 85, 69-85, 2003.

[27] Dursun, Ş., Özdemir, C., "Konya İl Merkezinde Gürültü Kirliliği Haritasının Hazırlanması" $97-$ 081, 4-24, Konya, 1999. 